\title{
Proceeding
}

Supplementary Issue: Spring Conferences of Sports Science. Costa Blanca Sports Science Events, 19-20 June 2020. Alicante, Spain.

\section{The educational value of the rules in five-a-side football}

\author{
FELICE DI DOMENICO 14 , ITALO SANNICANDRO², GAETANO ALTAVILLA ${ }^{1}$ \\ 1 University of Salerno, Italy \\ 2University of Foggia, Italy
}

\begin{abstract}
The rules of the game of team sports and the technical and tactical modalities applicable to them are indispensable for practicing sports in a competitive way. The correct competition arose from the automatic mechanism of the sanction following the infringement of a game rule which is also aided by the relational dynamics of the individual members of the group who claim the application of the rule to continue playing. The competition can also be self-regulated by the two groups that compete for the victory without even the referee's decisive action as always happens in training activities. This phenomenon is found only in those contexts where the rule is necessary and sufficient on its own to guarantee the orderly development of activities. The aim of the study is to identify the significant elements of the five-a-side football rules, and the related technical and tactical behaviours, to identify an inventory of significant behaviours. The method is documentary archive research for the analysis of the game rules of the team sport in question, and a subsequent comparative method among the grids of indicators, descriptors and weights that classify rule, technique and tactics. The expected results will focus on the fair presence of the significant elements and the commonality or discrepancy between team sports. The data is useful to measure the quantity of significant behaviours in order to qualitatively elaborate the value of each of them compared to the other current behaviours of the quantitative performance and to establish the connections.
\end{abstract}

Keywords: Game rules; Basic technique; Principles of individual and collective tactics.

\section{Cite this article as:}

Di Domenico, F., Sannicandro, I., \& Altavilla, G. (2020). The educational value of the rules in five-a-side football. Journal of Human Sport and Exercise, 15(3proc), S645-S655. doi:https://doi.org/10.14198//hse.2020.15.Proc3.17

Corresponding author. Department of Human, Philosophical and Education Sciences, University of Salerno, Italy.

E-mail: flcdidomenico@gmail.com

Supplementary Issue: Spring Conferences of Sports Science. Costa Blanca Sports Science Events, $19-20$ June 2020. Alicante, Spain.

JOURNAL OF HUMAN SPORT \& EXERCISE ISSN 1988-5202

(c) Faculty of Education. University of Alicante

doi:10.14198/jhse.2020.15.Proc3.17 


\section{INTRODUCTION}

Five-a-side football or futsal is an indoor sport. It has several aspects in common with football but, at the same time, it has its own characteristics that make this discipline specific. The number of game contrasts is greater in 5-a-side football; each player has the possibility to play the ball several times; pass are made more quickly in both offensive and defensive actions; the execution of technical gestures is much faster; the game tactic changes considerably (everyone attacks and everyone must defend); the score can change much faster and generally the games (especially amateur ones) end up with higher scores than football (Gréhaigne et al., 1999). The rules of the game and in particular some points that characterize it, determine the player's technical-tactical behaviour (Costa et al., 2010). Five-a-side football can be considered, in a certain sense, preparatory to 11-a-side football, since the individual fundamentals, as well as the principles of individual and collective tactics are the same as football but, since the spaces and times of play are relatively small, what a good soccer player does is the precision in the technical execution that is obtained with a constant specific training (Molinuevo, 2013; Polidoro et al., 2013). Being in possession of the technique of this sport means knowing how to control, move and kick the ball using all the parts of the body that the regulation allows to use. Before specifically analysing the significant elements of the game rules and the related technical and tactical behaviours, it is necessary to underline the importance of an "off the pitch" methodology (Trocchia et al., 2019). Not only is the working method, that is the way in which the training, the planned programs and the purely football aspects are used, but an off-field method is also necessary. Indeed, it is crucial and functional for what the trainer intends to propose on the playing field. The first element to consider is respect; start from here if you don't want to act casually. It is the first aspect on which to build the relationship with the players. It must be among all staff members, because in addition to being decisive for achieving important results, it becomes a signal to the players. The trainer cannot obtain it in an authoritarian way using only his role, he must give it to have it in return (Goulstone, 2000). Each player must know their task and be ready to do their utmost to achieve shared goals. The trainer in turn, must be willing to do his best to improve his players, for example with individual programs organized in detail, or with moments before the session to try to perfect an individual tactic gesture or behaviour. After each trainer has understood the true strength of personal attention towards each individual and thus, understood the true value of respect, he can move on to the rules, remembering that behaviour matters more than words. A precisely elaborated regulation is not necessary; one hundred rules can be written that are of little use. What matters is to give, or rather find, together with the group some rules and apply them without exception (Giordano et al., 2019; Isidori, 2008). The so-called behaviours that go beyond football, those indispensable in everyday life, are decisive. Also, in this context there is a scale of values. The rules must be clear, there are moments to be respected. It is usually a practice in a team for players to develop some sort of internal regulation (Sabalino, 2004). There is no single recipe, it is important that the coach understand which group he has in front of him (also based on the age of the boys) and guide them towards the ideal rules for them. An important concept that the coach must understand is that the team precedes the individual: therefore, any behaviour that goes in the opposite direction must be sanctioned. Punctuality and presence at the sessions, care of the material, cleaning in the dressing room can be part of the more general rules. Few rules and no exceptions. So, the duty of the trainer is to enforce what has been established together with the team, because if the trainer does not keep what has been decided, he loses credibility (Sheppard \& Young, 2006). He must be a fine observer of the different attitudes of his boys and act often in a preventive form. In addition, the trainer must evaluate all the group dynamics that occur during the week and intervene immediately according to what happens. The comparison is important, giving space to the players as it helps them grow. In fact, one of the goals of the coach is to bring the players to autonomy: autonomy in the management of the locker room, in the pre and post-game, in some moments of the session (Rossi et al., 2013). They need freedom, to be able to express themselves, on and off the pitch. Clearly, they also need a guide to support them in difficulties, but that pushes them to 
make decisions (Riela \& Polido, 2010). A clear, sincere and above all direct relationship is crucial. It is important to make them understand that the different interventions that the coach will do are not reproaches, but corrections, indications for becoming better (D'Isanto, 2016). It is by touching the right strings that players can be involved and convinced in the individual and therefore team improvement project (Milanovic et al., 2011). In summary therefore, the results are obtained when there is group cohesion and a sharing of objectives and rules. A good trainer must make his players independent and autonomous. In principle, the goal of each technician is to understand the qualities and qualities of their boys and try to raise them to maximum power. In addition, it must limit deficiencies through training and daily work. "We play to win", let's not forget this concept, it is the extremes that lead to error. Victory at all costs, thanks also to not exactly honest means, leads nowhere. The games must be played with the utmost commitment and attention, without exasperating everything (Rosso, 2018). Turning now to the "on the field" methodology, a trainer must know and transmit the dynamics of all gestures as well as being the master of didactics for the teaching of gestures. Several authors divide the soccer technique into various stages (Castagna et al., 2009). The first concerns the control and reception of the ball, the second concerns how to kick and pass the ball, the third concerns the header technique and the last phase the goalkeeper technique. The teaching of the technique must necessarily be oriented towards a fair balance between didactic proposals based on repeated exercise and those based on game situations. Each of these fundamentals will be analysed in detail in the central part of the work. Obviously, it is not enough to have great ball domination skills if all this is not expressed in a functional way, in a context in which there are companions and opponents who move in the times and spaces that the game determines (Aguiar et al., 2015). Therefore, technical skills must be expressed according to what the game requires. The concept of applied and individual and collective tactics is therefore particularly important. The 5-a-side football team tactics (which have more similarities with handball and basketball than with traditional football) are constantly evolving, with increasingly numerous patterns both in the defensive and in the offensive phase (Lhaksana, 2011). Each tactic has advantages and disadvantages and must be adapted to the technical level of the team, the game situations and the behaviour of the opponents; so motor control and learning is the base to develop the skills (Raiola, 2017, 2015, 2014, 2013, 2011ab).

There are several tactical principles classified in reference to the two main game phases. The principles of tactics in the possession phase are staggering, breadth, mobility, penetration and unpredictability. Those in the non-possession phase are: defensive staggering, delaying action, concentration, defensive balance, control and caution. Also, in this case we will describe the need to perform these game principles keeping in mind the regulation that makes 5 -a-side football specific.

\begin{abstract}
Aim of study
The aim of this study is to identify in the 5-a-side football team the significant elements of the game rules and the related technical tactical behaviours to be adopted in the various match situations. All this allows us to define an inventory of significant behaviours to be subjected to qualitative processing. The value of each of them will also be measured with respect to the other current behaviours of qualitative performance by establishing connections.
\end{abstract}

\title{
MATERIAL AND METHODS
}

On the one hand, the method involves archival research with a documentary approach for the analysis of the rules that characterize the team sport in question; on the other hand, it provides for a comparison between grids of indicators, descriptors and weights (i.e. the degree of connection between indicator and descriptor) that allows to classify the rule, technique and tactics. In the first phase, the analysis of the 5-a-side football rules was conducted, with which we tried to establish a connection with the technical and tactical aspects 
necessary to achieve the specific target. The identified rule represented the indicator, while the technical and tactical proposals represented the first and second descriptors respectively. The degree of connection between the indicator and the descriptor was then assessed, assigning a qualitative value between three choices: narrow, medium or low connection. In the second phase of the research, the relationship of each of the previously identified elements with the performance data was descriptively identified. In practice, the degree of physical commitment, the degree of strength and the speed for each of the indicators-descriptors identified were assessed, also assigning in this case a qualitative value among the possible alternatives: maximum, average and minimum commitment. The data is therefore useful to measure the quantity of significant behaviours to qualitatively elaborate the value of each of them compared to the other current behaviours of the quantitative performance and to establish the connections. The results may be useful for any reflections and focus on the reproducibility of the investigated mechanism to other social activities through an educational and training action.

\section{RESULTS}

Table1. Summary data.

\begin{tabular}{|c|c|c|c|c|c|c|}
\hline \multirow{2}{*}{$\begin{array}{l}\text { Indicator } \\
\text { Rules }\end{array}$} & \multirow{2}{*}{$\begin{array}{l}\text { 1st descriptor } \\
\text { Technical proposal }\end{array}$} & \multirow{2}{*}{$\begin{array}{l}\text { 2nd descriptor } \\
\text { Tactical proposal }\end{array}$} & \multirow{2}{*}{\begin{tabular}{|l|}
$\begin{array}{l}\text { Indicator- } \\
\text { descriptor } \\
\text { connection }\end{array}$ \\
Weight
\end{tabular}} & \multicolumn{3}{|c|}{ Connection with the performance data } \\
\hline & & & & $\begin{array}{l}\text { Degree of } \\
\text { physical } \\
\text { commitment }\end{array}$ & $\begin{array}{l}\text { Degree of } \\
\text { strength }\end{array}$ & $\begin{array}{l}\text { Degree } \\
\text { of speed }\end{array}$ \\
\hline $\begin{array}{l}\text { The reduction of } \\
\text { the playing space } \\
\text { and the number of } \\
\text { players on the } \\
\text { pitch. }\end{array}$ & $\begin{array}{l}\text { Recreate situations of } \\
\text { superiority and } \\
\text { numerical inferiority in } \\
\text { small spaces with a } \\
\text { reduction in the } \\
\text { number of touches }\end{array}$ & $\begin{array}{l}\text { Staggering during } \\
\text { possession and } \\
\text { non-possession of } \\
\text { the ball. } \\
\text { Define a game } \\
\text { system with precise } \\
\text { dictates both in the } \\
\text { offensive and } \\
\text { defensive phase }\end{array}$ & Narrow & Maximum & Maximum & Maximum \\
\hline $\begin{array}{l}\text { The game takes } \\
\text { place on fast } \\
\text { surfaces on which } \\
\text { the ball moves at } \\
\text { high speed. }\end{array}$ & $\begin{array}{l}\text { Ball control: receiving } \\
\text { and defending the } \\
\text { ball. }\end{array}$ & $\begin{array}{l}\text { Possession phase: } \\
\text { mobility, breadth } \\
\text { and depth. } \\
\text { Non-possession } \\
\text { phase: } \\
\text { concentration, } \\
\text { balance-control and } \\
\text { caution }\end{array}$ & Narrow & Maximum & Maximum & Maximum \\
\hline $\begin{array}{l}\text { Reduced game } \\
\text { times. } \\
\text { (Two halves of } 20 \\
\text { minutes each) }\end{array}$ & $\begin{array}{l}\text { A good technical level } \\
\text { is required in all } 7 \\
\text { basic fundamentals }\end{array}$ & $\begin{array}{l}\text { Define a rational, } \\
\text { elastic and } \\
\text { balanced game } \\
\text { system in the two } \\
\text { game phases }\end{array}$ & Narrow & Maximum & Maximum & Maximum \\
\hline $\begin{array}{l}\text { Ball } \\
\text { characteristics ( } n \\
{ }^{\circ} 4 \text { with controlled } \\
\text { rebound) }\end{array}$ & $\begin{array}{l}\text { Ball treatment and } \\
\text { awareness exercises }\end{array}$ & $\begin{array}{l}\text { Situational exercise } \\
\text { for the maintenance } \\
\text { of possession. } \\
\text { Ability to manage } \\
\text { the ball, with the } \\
\text { opponent, in one's } \\
\text { own space of action }\end{array}$ & Narrow & Medium & Medium & Maximum \\
\hline
\end{tabular}




\begin{tabular}{|c|c|c|c|c|c|c|}
\hline $\begin{array}{l}\text { Fast restart of the } \\
\text { game (max. } 4 \\
\text { sec.) }\end{array}$ & $\begin{array}{l}\text { The passage on the } \\
\text { figure (direct). } \\
\text { The passage in } \\
\text { space (indirect) }\end{array}$ & $\begin{array}{l}\text { Possession phase: } \\
\text { unpredictability, } \\
\text { mobility, breadth. } \\
\text { Non-possession } \\
\text { phase: defensive } \\
\text { staggering, delaying } \\
\text { action, goal } \\
\text { defence. }\end{array}$ & Narrow & Maximum & Maximum & Maximum \\
\hline $\begin{array}{l}\text { Throw-in is done } \\
\text { with the feet }\end{array}$ & $\begin{array}{l}\text { The passage on the } \\
\text { figure (direct). } \\
\text { The passage in } \\
\text { space (indirect) }\end{array}$ & $\begin{array}{l}\text { Possession phase: } \\
\text { unpredictability, } \\
\text { mobility, depth. } \\
\text { Non-possession } \\
\text { phase: delaying } \\
\text { action }\end{array}$ & Narrow & Medium & Medium & Maximum \\
\hline $\begin{array}{l}\text { Presence of the } \\
\text { free throw }\end{array}$ & $\begin{array}{l}\text { Exercise: } \\
\text { Frontal shot and shot } \\
\text { performed from } \\
\text { outside }\end{array}$ & $\begin{array}{l}\text { Consider the } \\
\text { positioning of the } \\
\text { goalkeeper, the } \\
\text { distance from the } \\
\text { soccer goal and the } \\
\text { best anatomical } \\
\text { surface for the } \\
\text { conclusion }\end{array}$ & Narrow & Maximum & Maximum & Maximum \\
\hline $\begin{array}{l}\text { The absence of } \\
\text { the offside }\end{array}$ & $\begin{array}{l}\text { The movement of } \\
\text { deception and the } \\
\text { intentional one } \\
\text { without a ball. } \\
\text { The passage in } \\
\text { space }\end{array}$ & $\begin{array}{l}\text { Possession phase: } \\
\text { depth-breadth, } \\
\text { unpredictability, } \\
\text { verticality. } \\
\text { Non-possession } \\
\text { phase: delaying } \\
\text { action, marking, } \\
\text { staggering and } \\
\text { indirect contrast }\end{array}$ & Narrow & Medium & Medium & Maximum \\
\hline $\begin{array}{l}\text { The limits of the } \\
\text { back pass to the } \\
\text { goalkeeper }\end{array}$ & $\begin{array}{l}\text { Ball conduction: free } \\
\text { and with opponent. } \\
\text { Dribbling skill }\end{array}$ & $\begin{array}{l}\text { Possession phase: } \\
\text { marking, defence } \\
\text { and control of the } \\
\text { ball, penetration. } \\
\text { Non-possession } \\
\text { phase: defensive } \\
\text { staggering, delaying } \\
\text { action }\end{array}$ & Narrow & Medium & Medium & Maximum \\
\hline $\begin{array}{l}\text { Temporary } \\
\text { expulsions (time } \\
\text { max. } 2 \text { minutes) }\end{array}$ & $\begin{array}{l}\text { Interception, indirect } \\
\text { contrast }\end{array}$ & $\begin{array}{l}\text { Negative transitions } \\
\text { (1vs2, 2vs3, 3vs4, } \\
\text { 1vs3, 2vs4) in the } \\
\text { non-possession } \\
\text { phase. } \\
\text { Positive transitions } \\
\text { (2 vs1, 3vs2, 3vs1). } \\
\text { Taking advantage of } \\
\text { numerical superiority }\end{array}$ & Narrow & Maximum & Medium & Maximum \\
\hline
\end{tabular}

\section{DISCUSSION}

The first game rule identified that characterizes 5 -a-side football concerns the playing space and the number of players on the pitch. By regulation, the length of the pitch (of wood or synthetic material) ranges from a minimum of 25 to a maximum of $42 \mathrm{~m}$, the width from 15 to $25 \mathrm{~m}$. The football goal measures $3 \mathrm{~m}$ wide by 2 $\mathrm{m}$ high. The players on the field are 5 for team, including the goalkeeper; for the game to be valid, there must 
be at least 3 players on the field per team. The use of a maximum of 7 reserve players is allowed. The expelled players can be replaced by the reserve ones, but only after that two actual minutes of play have elapsed since the expulsion; if, however, before the two minutes have elapsed, the team whose player has been sent off suffers a goal, then the trainer can immediately replace his player with the reserve (Benvenuti et al., 2010). A possible proposal of a technical nature that can accustom players to familiarize themselves with the size of the field and in collaboration with their teammates concerns training in small spaces with a limited number of touches, recreating situations of superiority or numerical inferiority. Clearly interested in ball control, passing and conducting. It obviously starts from the conduction, that is, the gesture that allows the player to dominate the ball and that also allows to improve the other fundamentals. In fact, foot-ball sensitivity must be improved by making the player safer. It is possible to work in frequency (numerous touches) or in amplitude (fewer touches) since by varying the type of touches it sensitizes the foot-ball contact more. It being understood that the rectilinear mode is the only one that allows to continue in the desired direction, the changes of direction are functional to avoid an opponent or bring the ball to a sector other than the one assumed at the start. Then it come to the fundamental pass for the construction of the action. To be productive, they must be performed at the right time, with imagination, precision and even with a little cunning. The passage should only be performed to the unmarked teammate, taking into account his movements, giving the ball the right speed, sufficient not to allow the opponent to intercept or anticipate it easily, but not so high as to prevent control by the teammate. Often the low pass is the most effective since the high pass, if it is not hit on the fly, forces the receiver to take precious time to control the ball. Finally, it is necessary to train reception or the ability to receive the ball with a part of the body in order to control and orient it through a cushioning phase, all to play it quickly. To perform the stop correctly, the player must quickly identify the direction from which the ball arrives to find himself already prepared to receive it, adapting the position of the body to it. He need to be able to both control the ball to hit it calmly and accurately and in its fast variant with opposing pressure. From a tactical point of view, it is necessary to define a game identity key by defining a scheme to be adopted in the competition where the trainer assigns specific tasks and functions to the players. Generally, a 1-3-1 system is adopted in the possession phase, which provides for a clear offensive reference (pivot) guaranteeing depth to the action but which at the same time can generate static action . A more congenial attack with the 1-4-0 system that does not offer points of reference to the opponents, favouring the possibility of attacking the free spaces generating difficulties in the opponent's defensive adaptations. On the other hand, it is very expensive from a physical point of view (Scandroglio, 2010). In the non-possession phase it is necessary to try all three defensive methods: the individual one (where the main opponent is the opponent to be marked; markings are assigned in relation to the characteristics of the attackers) the one with changes of marking (to reduce some disadvantages that generates the defence of an individual type) and finally the one with zone disposition (where each player is responsible for the area of the field that has been assigned to him and the opponents who are in that area). It is essential to learn the staggering movement both in an offensive and defensive key, occupying the playing field in the best way so that the player with the ball has the greatest number of plays possible. At the same time, it is necessary to ensure the greatest possible effectiveness for players without the ball in their position on the pitch. They must line up multiple lines to narrow the ground on which opponents can move freely. Another situation to work on is that of numerical inferiority. The situations of $1 \mathrm{vs} 2$ or even $1 \mathrm{vs} 3$ are frequent in this discipline: a defender must be taught what it means to decrease the space behind him, seeking the help of his teammates in folding or even that of the goalkeeper. The connection between indicator and descriptor as can be seen is very close. From a performance point of view, the degree of physical commitment, strength and speed is maximum because it requires high speed of movement, considerable physical strength, but above all also that of a mental nature (i.e. the ability to quickly perform observation, processing operations, choice and execution and specific resistance to the effort it has to sustain). Specific resistance to the effort he have to bear is also needed. 
The second rule identified concerns the playing surfaces on which the game takes place. These are fast surfaces on which the ball moves at high speed. All this determines the specific technical tactical behaviours of the soccer player and the physical effort he must make (D'Isanto et al., 2019). From a technical point of view, it is necessary to work on the control of the ball: both in the reception and in the defence phase. For the player, the fine sensitivity that allows to switch from a moment of relaxation to a moment of contraction is fundamental. So, dampen the impact of the ball on own body. From a tactical point of view, it is necessary to work on the transitions; players must be trained to minimize the time between possession and nonpossession. In an offensive key it is necessary to move in depth (conquering the space through forward pass that allow you to climb over the opposing defensive lines), breadth (taking advantage of the whole front of the field trying to open the defensive jerseys) and mobility (shake off in time and in the right spaces). Defensively it is necessary to concentrate (create density in the ball area by restricting the spaces to the attackers), balance (maintain optimal coverage through the correct arrangement regardless of the game system applied), control and caution (be aware of the advantages or disadvantages that the choice of adopt a certain behaviour). As before, from a performance point of view, the commitment is maximum in all three parameters.

There are two periods of play of 20 minutes each of actual play; the two teams have the possibility to request a minute of time out for each game time. The time available to direct the outcome of the match is reduced compared to football to 11. A good basic technique is needed; the aim is to be to bring our players to automate our tactical technical process (Altavilla et al., 2017). According to this, it is important to use various forms of exercises to achieve a single goal. On the tactical level, one must work especially on the non-possession phase in order not to be caught by surprise during the competition and to run the risk of chasing in the score with the risk of going too far forward, leaving room for the opponents to start a counterattack. From an individual point of view, to our player we should teach how to handle the opponent's attack and how to optimally position the body by evaluating further useful information (e.g. the opponent's strong foot). We should teach him how to mark an opponent in a $1 \mathrm{vs} 1$ and how to behave in case his marking has not produced the desired results (Severino et al., 2019). In particular, how to manage certain situations also based on the areas of the field where these episodes occur: a defensive behaviour performed on an opponent 10 meters away from own area will not be the same as one against an opponent 35 meters away, because the danger assessment and consequently, the choices to be made will have a different weight from one situation to another. The degree of physical commitment is maximum as well as that of physical strength and mental strength. Needless to say, the necessary speed of movement.

Another rule concerns the characteristics of the ball, also called controlled rebound ball. In order to be used during competitions, the 5-a-side soccer ball must have precise characteristics regarding shape, materials and physical properties. It must have a spherical shape: the total circumference of the ball cannot be less than 62 centimetres and must not exceed 64 . The weight of the ball must be between 400 and 440 grams and, before each championship match, it is always weighed. Finally, it is very important that the pressure of the balloon is always between 0.4 and 0.6 atmospheres. A controlled rebound ball must have all these precise characteristics in order to be suitable for use in indoor sports facilities and on sports wooden or linoleum parquet. It is very important that the ball respects these characteristics since a change in shape or weight could radically change its performance, for example by changing the rebound, the impact power or the maximum speed that can be acquired [6,9]. From a technical point of view, it is necessary to propose analytical sensitization exercises such as running with the sole, rolling inside and outside, driving in space. On the tactical level, a situation inherent in the construction from below should be recreated through central and lateral lanes. An exercise on short-long phrasing, a ball turn with movement of the teammates would also be fine. On the performance level, the physical and strength commitment is medium, variable according 
to the game requirements and the outcome of the race while the speed effort is necessarily maximum since the ball always moves at high speed.

Two other rules closely related to each other relate to the fast resumption of the game. The referee starts counting the 4 seconds when the athlete has the playable ball (e.g. the ball goes out, the player picks it up and brings the ball to the point where to beat the foul, from this moment the counting begins). If the team that has to put the ball back in play takes longer than 4 seconds to execute it, an indirect free kick will be awarded to the opposing team. In the specific case of the throw-in, this must necessarily be performed with the feet. If it is longer than 4 seconds to put the ball back into play, the throw-in will be awarded to the opposing team. On a technical level it is necessary to work on the fundamental of the passage. The passage must be precise, timely, easily admissible. Essential are exercises on direct and indirect passage (Lhaksana, 2011). In the first case, the passage is performed on the partner's feet. In the narrow marking the pass should be made on the foot opposite the side where the opponent is located, in order to allow the receiver to defend the receiver to better defend the ball. In the second case, the indirect passage is carried out on the direction of run of the teammate that receive. The optimal situation is obtained when the receiver controls the ball without slowing down the race oriented in space. On a tactical level, the horizontal passage is extremely dangerous especially if performed from the outside towards the centre. If intercepted he would cut out who kicked and who was to receive. In these cases, the recipient is instructed to move backwards by moving diagonally to offer a nonhorizontal passage. Unpredictability and offensive mobility are needed; It is therefore important that the opponents perceive different solutions through the execution of deception movements both collectively and individually. In the defensive phase, it is necessary to try to perform the delaying action, altering the game times of the opponents, slowing them down, making them waste time developing the game. Allows to recover defensive balance. On the physical plane, the physical effort and speed are maximum, the strength is medium.

Another rule concerns the presence of free throw. The cumulative fouls are 5 for each team. If a team reaches the fifth foul, from the sixth foul onwards, the opposing team will be entitled to one free throw for each foul suffered until the end of the time (at the end of the first half the fouls are reset for both teams). The free throw can be kicked from the penalty spot on the field or at the point where the foul is suffered, and the goalkeeper can exit the goal up to 5 meters from the ball. In the sessions we must periodically cut out moments dedicated to exercises on shooting on goal (Helsen et al., 1998). The right balance between precision and power is needed. In the shot of the instep is the technique of kicking that allows to give greater power to the ball, while the internal neck shot allows to give the ball curved trajectories as well as a remarkable precision. The runup is almost always oblique, more or less long, like loading based on the type of shot. The didactic guidelines that favour the restoration of a lack of precision in the execution of the shot, may be to invite the footballer to aim towards the entire goal mirror, to the right or left of the goalkeeper. The attacker who kicks with his left foot from the left and from the right with his right foot is advised to shoot towards the second post, so that if the ball comes out of the goal mirror, it can be corrected (Raiola \& D'lsanto, 2016). From the performance point of view, the degree of physical commitment is medium, while that of strength and speed is high.

Finally, in 5-a-side football there is no offside and the number of back passes to the goalkeeper is limited. A goalkeeper who is in his half of the court, after having divested himself of the ball, can no longer play the ball. He can play it a second time in 3 cases: in the first, only if the ball has been touched by an opponent; in the second case when it is he who goes to the opposing half of the field where he is a footballer like the others, and therefore he can play without the constraints of his role; finally in the third case if there is any resumption of the game that starts a new action (Sampaio et al., 2014). Since back passing is not allowed, the player must be unprejudiced. He must master the driving ability of the ball in advance and the discharge or 
transmission of the ball performed with the sole, the neck or the outside of the foot. Also important is the movement of the attacker's action without the ball through a movement of deception which precedes the moment in which he tries to overcome the opponent. In essence, it is a matter of making the opponent believe that he has chosen a solution to overcome it, which will subsequently be modified through a final movement which will then be defined as of intentional type (Schofield, 1983). The movement of the deception must elicit a reaction from the defender which will lead him to become unbalanced and which will therefore allow the attacker to overcome him on the counterattack. At the tactical level, during the possession phase, the principle of unmarking and mobility is necessary, introducing the concept of area of light and area of shadow. The light zone indicates the space in which the ball holder is able to see the teammate who has unmarked himself and possibly pass the ball to him. This space is continuously variable, in relation to the position and behaviour of the defender who marks the ball carrier, to the position and behaviour of the other defenders. The shaded area, on the other hand, is the area of the pitch immediately behind a defender that cannot be reached by ball holder pass. The closer the defender is to the ball, the greater the shaded area behind him. This area then becomes an unnecessary space for the team in possession (Gamonales et al., 2018). In terms of performance, the degree of physical commitment is high, rapidity of movement is required. Speed is closely related to motor speed, closely related to a subject's neuromuscular parameters.

\section{CONCLUSION}

In situation sports it is very useful to have a broad perceptual analysis to make effective decisions. Playing football also means having and knowing how to change one's level of psychophysiological activation, according to the needs to be tackled on the pitch (Sannicandro, 1999). 5-a-side football, like other team sports, is characterized by a strong interdependence of the tasks of the players on the pitch: everyone's performance is influenced by that of his teammates and vice versa. It is necessary to teach to play in an organized and coordinated way. Starting from the significant elements of the game rules, it was possible to identify a whole series of technical behaviours to be adopted and mastered. The technique must always be taught in the context of situations similar to those of the game. We know that only in about $40 \%$ of cases the imperfect technique is the determining factor for the loss of the ball; in the remaining $60 \%$ of cases, the error is mainly linked to the player's inability to adapt to different game situations and to his errors in the perception and decision-making (Wein, 2013). The technique, although important, is only one of the components that determine good performance. Tactical experience must also be considered as a fundamental requirement. Knowing how to read the game, understanding what is possible and what is best to do in a given situation is as important as learning and correctly executing a specific technique. The results emerged are useful for any reflections and focus on the reproducibility of the mechanism investigated to other social activities through an educational and training action.

\section{REFERENCES}

Aguiar, M., Gonçalves, B., Botelho, G., Lemmink, K., \& Sampaio, J. (2015). Footballers' movement behaviour during 2-, 3-, 4-and 5-a-side small-sided games. Journal of sports sciences, 33(12), 1259 1266. https://doi.org/10.1080/02640414.2015.1022571

Altavilla, G., Riela, L., Di Tore, A.P., Raiola, G. (2017). The physical effort required from professional football players in different playing positions. Journal of Physical Education and Sport, 17 (3), n. 200, 2007-2012.

Benvenuti, C., Minganti, C., Condello, G., Capranica, L., \& Tessitore, A. (2010). Agility assessment in female futsal and soccer players. Medicina, 46(6), 415. https://doi.org/10.3390/medicina46060058 
Castagna, Carlo, et al. "Match demands of professional Futsal: a case study." Journal of Science and medicine in Sport 12.4 (2009): 490-494.

Costa, I., Garganta, J., Greco, P., Mesquita, I., Silva, B., Muller, E., ... \& Seabra, A. (2010). Analysis of tactical behaviours in small-sided soccer games: Comparative study between goalposts of society soccer and futsal. The Open Sports Sciences Journal, 3(1). https://doi.org/10.2174/1875399X010030100010

Del Nista P.L., Parker J., Tasselli A., In perfetto equilibrio. Pensiero e azione per un corpo intelligente, D’Anna, (2011), Messina-Firenze.

D'Isanto, T., D'Elia, F., Raiola, G., Altavilla, G. (2019). Assessment of sport performance: Theoretical aspects and practical indications. Sport Mont, 17 (1), 79-82.

D'Isanto, T. (2016) Pedagogical value of the body and physical activity in childhood, Sport Science, 9, pp. 13-18.

Gamonales, J. M., Muñoz-Jiménez, J., León-Guzmán, K., \& Ibáñez, S. J. (2018). 5-a-Side Football for individuals with visual impairments: a review of the literature. European Journal of Adapted Physical Activity, 11(1). https://doi.org/10.5507/euj.2018.004

Giannattasio N., Quattrini M., II calcio a 5, Eco, 2004.

Giordano, L., Federici, A., Valentini, M., \& D'Elia, F. (2019). Dribbling in football: Confronting learning theories. Journal of Human Sport and Exercise, 14(2proc), S228-S232. https://doi.org/10.14198/jhse.2019.14.Proc2.10

Goulstone, J. (2000). The working-class origins of modern football. The International Journal of the History of Sport, 17(1), 135-143. https://doi.org/10.1080/09523360008714117

Gréhaigne, J. F., Godbout, P., \& Bouthier, D. (1999). The foundations of tactics and strategy in team sports. Journal of teaching in physical education. https://doi.org/10.1123/itpe.18.2.159

Helsen, W. F., Starkes, J. L., \& Hodges, N. J. (1998). Team sports and the theory of deliberate practice. Journal of Sport and Exercise psychology, 20(1), 12-34. https://doi.org/10.1123/jsep.20.1.12

Isidori, Emanuele, and Antonio Fraile. "Educazione, sport e valori." Un approccio critico-riflessivo. Roma: Aracne (2008).

Lhaksana J. Taktik \& Strategi futsal modern. Be Champion, 2011.

Milanović, Z., Sporiš, G., Trajković, N., \& Fiorentini, F. (2011). Differences in agility performance between futsal and soccer players. Sport Sci, 4(2), 55-59.

Molinuevo J.S., Le azioni di gioco nel calcio a 5, Calzetti Mariucci, 2007.

Polidoro, L., Bianchi, F., Di Tore, P. A., \& Raiola, G. (2013). Futsal training by videoanalysis. . Journal of Human Sport and Exercise, 8(2proc), S290-S296. https://doi.org/10.4100/jhse.2012.8.proc2.31

Raiola, G. (2017) Motor learning and teaching method, Journal of Physical Education and Sport, 17, art. no. 236, pp. 2239-2243.

Raiola, G., \& D'Isanto, T. (2017). Assessment of periodization training in soccer. Journal of Human Sport and Exercise, 11(1proc), S267-S278. https://doi.org/10.14198/ihse.2016.11.Proc1.19

Raiola, G. (2015). Sport skills and mental health. Journal of Human Sport and Exercise, 10(1 proc), S369S376. https://doi.org/10.14198//hse.2015.10.Proc1.27

Raiola, G. (2014) Motor control and learning skills according to cognitive and ecological dynamic approach in a vision on behaviorism, cognitive, Gestalt and phenomenology theories, Mediterranean Journal of Social Sciences, 5 (15), pp. 504-506. https://doi.org/10.5901/mjss.2014.v5n15p504

Raiola, G. (2013) Body knowledge and motor skills, Knowledge Cultures, 1 (6), pp. 64-72.

Raiola, G. (2011b) A study on Italian primary school rules: Neurophysiological and didactics aspects on physical education and sport, Journal of Physical Education and Sport, 11 (2), pp. 43-48.

Raiola, G. (2011a) Study between neurophysiological aspects and regulation documents on preschool in Italy, Journal of Physical Education and Sport, 11 (1), pp. 42-47. 
Riela L., Polido D., Coordinazione, velocità e finalizzazioni veloci per il calcio a 5. Con appendice di elementi di tecnica del portiere, Calzetti Mariucci, 2010.

Rossi, Matteo, Alkis Thrassou, and Demetris Vrontis. "Football performance and strategic choices in Italy and beyond." International Journal of Organizational Analysis 21.4 (2013): 546-564. https://doi.org/10.1108/ijoa-04-2013-0659

Rosso, G. (2018). L'apprendimento dei fondamentali individuali del gioco del calcio riferito a ragazzi in età compresa fra i dieci e i dodici anni [Learning the individual fundamentals of the game of football refers to children between the ages of ten and twelve]. Youcanprint.

Sabalino A., (2004). Tecnica, tattica e condizionamento fisico per il calcio a 5. Metodo integrale di allenamento per il precampionato e la stagione agonistica, Calzetti Mariucci.

Sampaio, J. E., Lago, C., Gonçalves, B., Maçãs, V. M., \& Leite, N. (2014). Effects of pacing, status and unbalance in time motion variables, heart rate and tactical behaviour when playing 5 -a-side football small-sided games. Journal of science and medicine in sport, 17(2), 229-233. https://doi.org/10.1016/j.jsams.2013.04.005

Sannicandro I. "Test e metodiche di valutazione atletica di una squadra di calcio a 5." Notiziario del Settore Tecnico (1999): 32-35.

Scandroglio, R. (2010). Come migliorare tecnica e tattica con il metodo dei movimenti fondamentali [How to improve technique and tactics with the fundamental movement method]. Ares.

Schofield, J. A. (1983). Performance and attendance at professional team sports. Journal of Sport Behavior, 6(4), 196.

Severino, N. C., Cassese, F. P., Ceciliani, A., D'Elia, F., \& Di Tore, A. P. (2019). Psychophysical benefits of recreational five-a-side football. Journal of Human Sport and Exercise, 14(2proc), S206-S214. https://doi.org/10.14198/ihse.2019.14.proc2.07

Sheppard, JM, Young WB. (2006). Agility literature review: classifications, training and testing. Journal of Sport Sciences, 24(9), 919-932. https://doi.org/10.1080/02640410500457109

Trocchia, T., Mariani, A. M., Pignato, S., \& D'Elia, F. (2019). 1 versus 1 in football after 20 years. Journal of Human Sport and Exercise, 14(4proc), S686-S690. https://doi.org/10.14198//hse.2019.14.proc4.28

Wein H., (2013). II calcio a misura dei ragazzi, Ed. Mediterranee.

\section{(9) $\odot \Theta \Theta$}

This work is licensed under a Attribution-NonCommercial-NoDerivatives 4.0 International (CC BY-NC-ND 4.0). 